\title{
Analysis of risks in a Learning Management System: A case study in the Spanish National University of Distance Education (UNED)
}

\author{
Esteban Vázquez-Cano ${ }^{1 *}$, M. $^{a}$ Luisa Sevillano García ${ }^{2}$ \\ ${ }^{1}$ Department Didactics and School Organization, Spanish National University of Distance Education (UNED), \\ Spain \{evazquez@edu.uned.es\} (D) \\ 2Department Didactics and School Organization, Spanish National University of Distance Education (UNED), \\ Spain \{mlsevillano@edu.uned.es\}
}

Received on 27 October; revised on 28 October; accepted on 3 November; published on 15 January

DOI: 10.7821/naer.2015.1.107

\begin{abstract}
This article presents a research that examines the university students' risk perception when using a Learning Management System called "aLF" and implemented by the Spanish National University of Distance Education (UNED) for the development of its university distance studies. The development of comprehensive Learning Management Systems for teachinglearning distance practices in the European Higher Education Area (EHEA) is a challenge for universities all around Europe. For this reason, it is necessary to analyze not only the benefits that involve these environments but the risks perceived by its users to improve teaching methods and design better user interfaces. Through a quantitative method, we test 588 students' opinions about their risks perceptions when using this LMS to study the University degree in Pedagogy. Results show that main risks are concentrated in two dimensions: dimension 1 "basic or general" with high incidence of "fear of making mistakes" and "ignorance of the course content; and dimension 2 "own and beyond students' circumstances" where it is important to stand out the risks not directly controlled by the students: "warning from the authorities for not developing the program", "isolation from teachers" and "delegation of control".
\end{abstract}

KEYWORDS: LEARNING MANAGEMENT SYSTEMS, RISKS, EUROPEAN HIGHER EDUCATION AREA, DISTANCE EDUCATION.

\section{INTRODUCTION}

The design of learning experiences within online programs is a continuously evolving area (Brindley, Walti \& Blaschke, 2009; Dodda \& Antonenkob, 2012; Shih, Feng \& Tsai, 2008; Stahl, Koschmann \& Suthers, 2006). Quality requirements of Higher Education and the need for the assurance of learning outcomes are increasing the challenges with which online universities have to face (Ananiadou \& Claro, 2009; Baker, 2003; Park, Nam \& Cha, 2012; Sabry \& Baldwin, 2003).

Universities are in a process of transformation toward a

${ }^{*}$ To whom correspondence should be addressed:

Facultad de Educación. (UNED)

Dpto. Didáctica. Organización Escolar y Didácticas Especiales.

C/Juan del Rosal, 14 (28040) Madrid. teaching model, which enhances the independent work of student along with collaborative practices, and virtual learning models are becoming an increasingly important role in these processes. To meet these challenges, virtual campuses are promoting learning methodologies that prioritize learning "through interactions among students" (Gómez \& RodríguezMarciel, 2012; Moyle, 2010; Stahl, Koschmann \& Suthers, 2006) and contribute to the development and practice of teamwork competencies. It is true that distance learning and, specifically, online education, rather than an alternative, has become a global trend of training, but at the same time, in recent years, a more social and interdependent learning among members of university communities is necessary.

In this digital context, digital platforms are increasingly organizing our lives; according to Rushkoff (2010), individuals who do not understand the inner workings of these procedures and cannot handle them properly end up being marginalized and subjected to some degree in the fields of power. If you cannot access the source code of technology, thinking machines may overdo. The current world literature has a big number of references on the use, application, and benefits of learning through Information and Communication Technologies (ICT) in almost all stages of education. e-Learning activities across tertiary education institutions are very diverse, with programs located at different points of the e-learning spectrum ranging from none or trivial online presence to fully online provision. Most studies establish that educational technology can play a social role in bridging the achievement gap between students, as well as promoting higher-order thinking skills, and probably, technology-rich learning environments can promote more effectively social-constructivist educational goals, such as higher-order thinking skills, learning motivation, and teamwork, in comparison to traditional settings (Jackson et al, 2006; Rosen, 2009; Rosen \& Rimor, 2009; Rosen \& Salomon, 2007; Warschauer, 2003; Warschauer \& Matuchniak, 2010).

This new reality has the potential to significantly impact how we design learning experiences if we take advantage of opportunities for connectivity. By incorporating 2.0 tools on Learning Management Systems (LMS), teachers also incorporate the new literacies that are becoming part of citizens in virtual contexts (Álvarez, 2001; Fletcher, 2007; Glover \& Oliver, 2008; Hahn, 2008). In the progress of integrating 
collaborative practices in distance learning, Learning Management System (LMS) offer different levels of interaction and possibilities for developing active learning. Innovation is not just the application of results of research and development to high standards but also the result of entrepreneurial and strategic decision making, organizational and professional development, and imaginative capabilities, and to this end, the forms of design learning elements are important conditions (Georgina \& Olson, 2010; Kopcha, 2012; Macdonald \& Poniatowska, 2011; Rovai \& Downey, 2010).

Despite all, LMS are not alike, and they can be used in different ways. However, a common idea behind LMS is that elearning is organized and managed within an integrated system. Different tools are integrated in a single system, which offers all necessary tools to run and manage virtual learning and teaching processes. LMS typically offer discussion forums, file sharing, management of assignments, lesson plans, syllabus, chat, and so on-tools that are very productive in learning. However, at the same time, it is also necessary to unravel the student's perception of risks of this type of virtual environments.

Global studies regarding student's risk perception on LMS are not very abundant and require field studies to unravel the risks of these environments on users. Recent studies have described emotional and motivational experiences students encountered during computer-supported learning projects, which can also cause negative effects (Artino, 2008; Artino \& Stephens, 2007; Hickey, Moore, \& Pellegrino, 2001; Järvenoja \& Järvelä, 2005; Sierpinska, Bobos \& Knipping, 2008). In particular, some computer-supported collaborative learning environments may interfere with students' willingness to engage in the project. They may also experience stress and frustration in collaborating with people who they do not know well (Curtis \& Lawson, 2001).

\subsection{Learning Management Systems and social interaction}

A LMS is a category of products designed to bring interactive technology to teaching-learning process (Daniels, 2009; Garrison \& Vaughan, 2008; Weller, 2007). A full-fledged LMS addresses three major requirements: first, it is a completely realized, networked digital environment that includes interactive interfaces for both teachers and students. Second, a LMS provides the content of the curriculum and assessments for teaching and learning in digital form. Third, a LMS includes special tools for managing classroom activity. A robust LMS should be able to do the following: centralize and automate administration, use self-service and self-guided services, assemble and deliver learning content rapidly, consolidate training initiatives on a Web-based platform, support portability and standards, personalize content, and enable knowledge reuse. Therefore, a LMS should integrate with other enterprise application solutions, enabling management to measure the impact, effectiveness, and cost of training initiatives (Ellis, 2009).

The new LMS differ from the Course Delivery LMS in terms of classroom operation and pedagogical support. Through the monitoring of assignments and assessment, new LMS offer tools for management of the classroom by the teacher and real-time evaluation of students. These new LMS should integrate three types of presence: social, cognitive, and teaching (Traphagan et al., 2010). "Social presence" is the way students cope socially and emotionally to a virtual learning community. "Cognitive presence," however, is how to build their knowledge through reflection and communication processes. The "presence of education,” finally, is one that directly or indirectly facilitates social interaction and simulation in the cognitive process.

The presence enables the coordination of activities to generate learning in LMS (Rourke et al., 2001). Social interaction in virtual environments, with both other students and the teacher, has a marked influence on the behavior of students. Kreijns et al. (2002) and Hrastinski (2006) note that social interaction flows when the LMS allows specific informal interaction, as occurs naturally in the real campus. One of the challenges of online education would allow natural interaction student-student in the virtual world. According to Dirkx and Smith (2004), in theory, online collaborative activities could be considered as the key to this new learning paradigm.

In these collaborative digital contexts, students do report experiencing a range of emotions, risks, and frustration (Do \& Schallert, 2004; Pekrun, Goetz, Titz \& Perry, 2002). Despite the advantages reported in literature about digital collaborative learning methodologies in terms of social and psychological benefits (Roberts, 2005), students engaged in collaborative digital learning activities can feel a high level of frustration facing different risks.

\subsection{Study context: The UNED LMS: “aLF”}

The LMS called aLF (https://www.innova.uned.es/servicios/alf/) is a platform based on open standards (OpenACS, the Open Architecture Community System) and has been developed entirely within free software principles. The appeal of in-house and open source sometimes lies in perceived inadequate functionality or pedagogic limitations of commercial offerings, despite platform functionality becoming increasingly customizable.

Its main contributions are security, scalability, extensibility, and low learning curve. It has now migrated to .LRN, which is the most widely used free software worldwide for distance learning. It is originally developed at MIT (Massachusetts Institute of Technology), to provide a collaboration tool that is flexible and innovative, along with scalable infrastructure development, necessary for growth. The software is backed by "The .LRN Consortium", a global organization formed by renowned institutions and companies around the world working together to coordinate the development of software, providing quality and new guidelines in education. LRN is used by organizations and universities, such as MIT Sloan (Massachusetts, USA), Harvard University Kennedy School of Government (Massachusetts, USA), University of Bergen (Norway), University of Heidelberg (Germany), University of Valencia (Spain), UCLA School of Medicine (California, USA), University of Galileo (Guatemala) and the National University of Distance Education (UNED) in Spain.

aLF facilitates the student to make good use of resources available over the Internet to alleviate the difficulties offered by distance learning model. This provides the necessary tools for both faculty and students, finding ways to combine individual work and cooperative learning. aLF offers different types of virtual learning environments: virtual courses and virtual communities. Each subject has an online space or online course. Both of them are didactic and evaluative environments in which contents, resources, and activities of the subject are organized. Within each virtual course, students can find the following: teacher(s) of the subject, tutor, network support tutor, and 
students of the subject. Teaching team of the course is responsible for the design and program of the subject, as well as for developing contents, and the final students' assessment. The virtual tutor of the course deals with mentoring, monitoring, and correction of continuous assessment tests proposed by the teaching team.

The network support tutor is responsible for solving problems using the digital tools of the platform during the course through a specific forum. Within the virtual course, study guide, calendar or schedule, sequence of planning activities, delivery of activities, online tests and quizzes, and communication tools (mainly the notice board of the teaching team, the thematic forums, and one forum exclusively for students) are offered. Virtual communities are relational environments not evaluative or confined to any particular matter or subject.

The main functions of these collective groups are virtual collaboration and communication (eg, virtual communities for new students reception), involving all new students in each faculty or school with the intention of accompanying them throughout their first year and thus facilitate their integration into the methodology of distance and virtual education. The main features offered by aLF are the following: management of working groups on request, shared storage space, organization of the contents, planning activities, evaluation and self-evaluation, automatic notification service, design of surveys, news release planned, and personal and public portal user configurable. The platform is characterized by presenting categorized information and resources. It is a powerful environment to support learning management courses and communities.

aLF structure is based on the following functionalities: forums, news, chat, bulletin board, messages, study guides, documents, activities, scores and assessments (Figure 1).

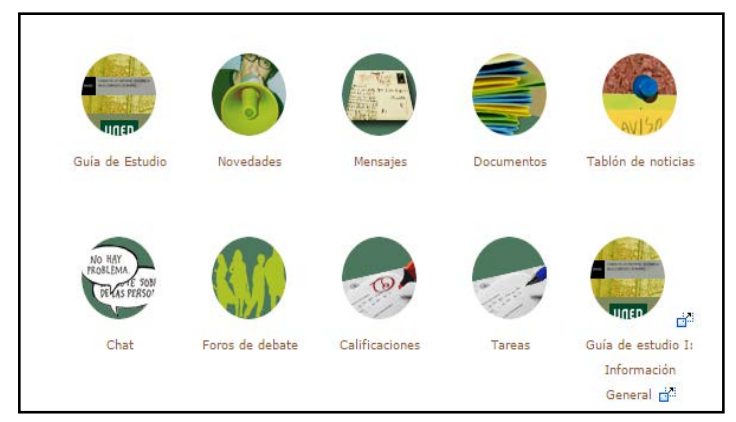

Figure 1. aLF Learning environment

\subsection{Objectives}

This research aims to estimate the perception of risks among students involved in a LMS developed in the Spanish National University of Distance Education (UNED). The study addressed the following objectives:

To analyze two risk dimensions: "general or basic risks" (not controlled by the students) and "own and beyond students' circumstances" perceived as risks that could be controlled by the students and/or Higher Education institutions.

To determine the most significant variables in students' risk perception according to both dimensions with special emphasis on risks in dimension 2 than could be minimize by higher education institutions and professors/tutors' intervention.

\section{METHOD}

During 2012-2014, the authors of this study decided to study the risks perceived by our students in the university degree of Pedagogy in relation to the use of LMS-aLF in distance university studies. Data were collected using a digital-based questionnaire uploaded in the LMS-aLF. The questionnaire was distributed to 778 second-year students when they began the academic year through an induction session of virtual tutor through e-mail and forum messages.

The questionnaire included three sections: competencies in ICT, risks of use of LMS-aLF for developing university studies, and barriers when using the LMS. Student variables included the students' self-rating of skills in the use of ICT, students' views on the contribution of LMS to develop university studies, and the power of LMS on creating creative learning environments. This questionnaire aims to establish the barriers' factors themselves and the degree of intensity with which they act as both internal and external forces when using LMS-aLF. To this end, 15 items were initially established to measure different factors. With the aim of strengthening the validity of the item contents, they were evaluated by ten judges and the feedback used to reduce the items to 8: 1 . Fear of making mistakes. 2 . Ignorance of the course content. 3. Open ends and lack of correct answers. 4. Criticism of the educational community. 5. Isolation from teachers. 6. Warning from the authorities for not developing the program. 7. Delegation of control. 8. Difficulty for students.

The Likert items consisted of four point scales: slight, low, moderate and high. In short, the university students completing the questionnaire were asked to indicate the extent to which they agreed or disagreed with the different statements. The questionnaire was completed during the second semester, and results were downloaded from aLF for their analysis once the academic year was finished.

About 608 questionnaires were validated, and factor analysis was developed using SPSS. A final sample of 588 cases were processed (Table 1).

Table 1. Case Processing Summary and Model Summary

\begin{tabular}{lr}
\hline \multicolumn{2}{c}{ Case Processing Summary } \\
\hline Valid Active Cases $^{\text {Active Cases with Missing Values }}{ }^{\mathrm{a}}$ & 588 \\
Supplementary Cases & 20 \\
Total & 008 \\
Cases Used in Analysis & 588 \\
\hline a. Excluded case(s): 9698112194277388401424426439 \\
462474491504509561563567578589. \\
\hline
\end{tabular}

The questionnaire's statistical guarantees were studied. The item-total correlation of the dimension was analyzed to eliminate those items with a correlation coefficient of below 0.2. In addition, the reliability of the scale was analyzed using the Cronbach's Alpha Test (.861).

Next, a factor analysis of principal components was conducted to determine the internal structure of the questionnaire. However, before carrying out the analysis, and as a prior statistical requisite that guarantees correct application, a series of other tests were performed: First, Bartlett's test of sphericity (.841 $\mathrm{p}<0.001)$ taking a 99\% level of significance and the Kaiser-Mayer-Olkin sampling adequacy measure (.797) were found to be suitable when analyzing the factorial structure of the 
scale using the Varimax with Kaiser Normalization method for the principal component analysis.

\section{RESULTS}

We consider dimension 1, as "general or basic" risks and dimension 2, as "own and beyond" students' circumstances perceived as risks. Kaiser's rule of retaining factors with eigenvalues larger than 1.00 was used in this analysis as the default. As the eigenvalues for the two principal components with eigenvalues of 4.059 and 1.005 were retained.

Table 2. Research Model Summary

\begin{tabular}{lccc}
\hline Model Summary & & \multicolumn{2}{c}{ Variance } \\
\hline & & Total & $\%$ \\
Dimension & Cronbach's Alpha & (Eigenvalue) & of Variance \\
1 &, 861 & 4,059 & 50,737 \\
2 &, 005 & 1,005 & 12,559 \\
Total &, $917^{\text {a }}$ & 5,064 & 63,296 \\
\hline
\end{tabular}

a. Total Cronbach's Alpha is based on the total Eigenvalue.

Table 3 contains the unrotated factor loadings, which are the correlations between the variable and the factor. Because these are correlations, possible values range from -1 to +1 . On the /format subcommand, we used the option blank (.30), which tells SPSS not to print any of the correlations that are .3 or less. This makes the output easier to read by removing the clutter of low correlations that are probably not meaningful anyway.

Table 3. Correlations matrix

\begin{tabular}{ccccccccc}
\hline \multicolumn{10}{c}{ Correlations Original Variables } \\
\hline & $\mathbf{1}$ & $\mathbf{2}$ & $\mathbf{3}$ & $\mathbf{4}$ & $\mathbf{5}$ & $\mathbf{6}$ & $\mathbf{7}$ & $\mathbf{8}$ \\
$\mathbf{1}$ & 1,000 &, 517 &, 455 &, 374 &, 373 &, 329 &, 188 &, 316 \\
$\mathbf{2}$ &, 517 & 1,000 &, 543 &, 398 &, 381 &, 410 &, 300 &, 389 \\
$\mathbf{3}$ &, 455 &, 543 & 1,000 &, 460 &, 470 &, 446 &, 390 &, 411 \\
$\mathbf{4}$ &, 374 &, 398 &, 460 & 1,000 &, 919 &, 462 &, 391 &, 430 \\
$\mathbf{5}$ &, 373 &, 381 &, 470 &, 919 & 1,000 &, 476 &, 403 &, 430 \\
$\mathbf{6}$ &, 329 &, 410 &, 446 &, 462 &, 476 & 1,000 &, 417 &, 434 \\
$\mathbf{7}$ &, 188 &, 300 &, 390 &, 391 &, 403 &, 417 & 1,000 &, 464 \\
$\mathbf{8}$ &, 316 &, 389 &, 411 &, 430 &, 430 &, 434 &, 464 & 1,000 \\
\hline
\end{tabular}

Variables: 1. Fear of making mistakes. 2. Ignorance of the course content. 3. Open ends and lack of correct answers. 4. Criticism of the educational community. 5. Isolation from teachers. 6. Warning from the authorities for not developing the program. 7. Delegation of control. 8. Difficulty for students.

Table 4 shows the rotated component matrix and establishes the correlation of each variable with each factor. Using that rule, based on our interpretation of the rotated factor loading table, we find that four variables seem to load strongly onto dimension 1 : "open ends and lack of correct answers" (.740); "criticism of the educational community" (.814); "isolation from teachers" (.815) and "warning from the authorities for not developing the program” (.710). Items that load strongly onto dimension 2 are: "fear of making mistakes" (.588) and "ignorance of the course content” (.495).
Table 4. Rotated factor matrix

\begin{tabular}{ccc}
\hline \multicolumn{3}{c}{ Rotated Factor Matrix } \\
\hline Variables & $\mathbf{1}$ & Factor \\
1 &, 609 & $\mathbf{2}$ \\
2 &, 692 &, 588 \\
3 &, 740 &, 495 \\
4 &, 814 &, 252 \\
5 &, 815 &,- 311 \\
6 &, 710 &,- 324 \\
7 &, 612 &,- 066 \\
8 &, 681 &,- 374 \\
\hline
\end{tabular}

Factor 1: General or Basic Risks (not controlled by the student) Factor 2: Risks controlled by the student.

Variables: 1. Fear of making mistakes. 2. Ignorance of the course content. 3. Open ends and lack of correct answers. 4. Criticism of the educational community. 5. Isolation from teachers. 6. Warning from the authorities for not developing the program. 7. Delegation of control. 8. Difficulty for students. Extraction Method: Principal Axis Factoring. Rotation Method: Varimax with Kaiser Normalization.

a. Rotation converged in 3 iterations.

The eight risk factors are reduced to 2 dimensions with abstract meaning: dimension 1 and dimension 2. Table 5 displays the frequency, the quantification value assigned, the centroid coordinates, and the vector coordinates of each risk.

We can observed that that most cases are located near the centroid $(0,0)$, with the majority of cases located between -3 and 5 on dimension 1 and between -4 and 6 on dimension 2 .

Table 5. Vector coordinates

\begin{tabular}{|c|c|c|c|c|c|c|}
\hline & \multicolumn{3}{|c|}{$\begin{array}{c}\text { Centroid } \\
\text { Coordinates }\end{array}$} & \multicolumn{3}{|c|}{$\begin{array}{c}\text { Total } \\
\text { (Vector Coordinates) }\end{array}$} \\
\hline & \multicolumn{2}{|c|}{ Factor } & \multirow[b]{2}{*}{ Mean } & \multicolumn{2}{|c|}{ Factor } & \multirow[b]{2}{*}{ Total } \\
\hline & 1 & 2 & & 1 & 2 & \\
\hline 1 & ,368 & ,382 & ,375 & ,361 & 375 & ,736 \\
\hline 2 & ,487 & ,239 & 363 & ,485 & ,234 & ,719 \\
\hline 3 & ,558 & ,088 & ,323 & ,555 & ,057 & ,611 \\
\hline 4 & 658 & ,080 & ,369 & ,658 & ,078 & ,736 \\
\hline 5 & ,666 & ,090 & ,378 & ,666 & ,085 & ,751 \\
\hline 6 &, 500 & ,018 & ,259 &, 500 & ,012 & ,512 \\
\hline 7 & 375, & 136, & 255, & 375, & 135, & ,510 \\
\hline 8 & ,461 & ,037 & ,249 & ,460 & ,029 & ,489 \\
\hline Active Total & 4,07 & 1,07 & 2,57 & 4,05 & 1,00 & 5,06 \\
\hline$\%$ of Variance & 50,92 & 13,38 & 32,15 & 50,73 & 12,55 & 63,29 \\
\hline \multicolumn{7}{|c|}{$\begin{array}{l}\text { Variables: } 1 \text {. Fear of making mistakes. } 2 \text {. Ignorance of the course } \\
\text { content. 3. Open ends and lack of correct answers. } 4 \text {. Criticism of } \\
\text { the educational community. 5. Isolation from teachers. } 6 \text {. Warning } \\
\text { from the authorities for not developing the program. } 7 \text {. Delegation } \\
\text { of control. 8. Difficulty for students. }\end{array}$} \\
\hline
\end{tabular}

Figure 1 shows the coordinates for each item on each dimension. We can see how the items related to one another and to the two dimensions. We can see that the first three items tend to coalesce together in the upper range of both dimensions 1 and 2 , whereas the other four items tend to coalesce at the lower range of dimension 1 , and they tend to vary substantially along dimension 2. 


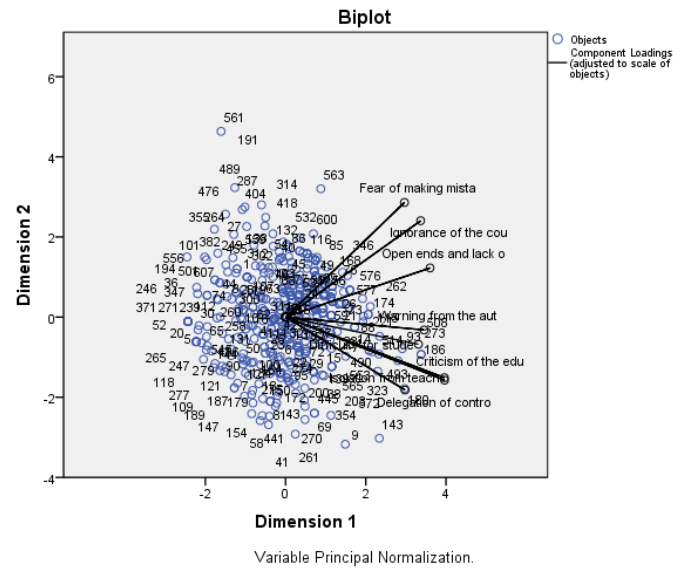

Figure 2. Vectors dimensions

The analysis of both dimensions of the vectors as in the case numbers of both dimensions, we can observe the following:

All factors are positively charged in Dimension 1.

The basic or general risks could be summarize in Figure 3.

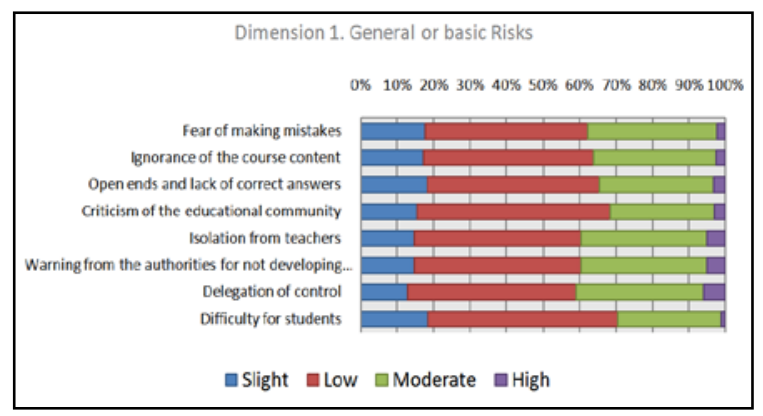

Figure 3. Dimension 1. General or basic risks

With respect to Dimension 2:

Have a positive charge: 1. Fear of making mistakes. 2. Ignorance of the course content. 3. Open ends and lack of correct answers.

Have a negative charge: 4 . Criticism of the educational community. 5. Isolation from teachers. 6 . Warning from the authorities for not developing the program. 7. Delegation of control. 8. Difficulty for students.

We make the following interpretation of the dimensions:

Dimension 1: Risk basic or general.

Dimension 2: Influence on the risk of "own and beyond students' circumstances" that could be controlled by the students and/or Higher Education institutions.

In this sense, we can establish the following factors' interpretation:

Own factors: positive charged in dimension 2: 1. Fear of making mistakes. 2. Ignorance of the course content.

Beyond factors: negative charged in dimension 2: 4. Criticism of the educational community. 5. Isolation from teachers. 6 .
Warning from the authorities for not developing the program. 7. Delegation of control. 8. Difficulty for students.

The angle between the vectors of the risks is an indicator of "lankiness" of them. This implies the following:

It is remarkable the separation between own and beyond factors. Both form independent clusters, being relatively distant from each other.

The proximity of "isolation" and "criticism" factors can be highlighted. These two risks provide very similar information; thus, there is high consistency in the responses given by students to these two questions.

Own and beyond factors could be improved through new forums and chat rooms management. For this purpose, an appropriate and constant training is fundamental to equip tutors with necessary facilitation skills towards enhancing learnercentered interaction in the web-based learning environment. This sets an atmosphere for mutual respect and encourages proactive participation from learners. As distance students tend to feel lonely throughout their journey of acquiring knowledge, tutor plays a vital role to provide various methods of interaction in web-based learning e.g. electronic office hours via synchronous chats. Creating learning environment which is perceived as facilitating "safe" communication is essential. Therefore, tutors could share own experiences related to the subject, promote a constant response to students queries in the forums, encourage learners to lead and participate in discussions ( $\mathrm{Wu} \& \mathrm{Teoh}$, 2008). High level of interaction in online learning environment is desirable and positively affects the efficacy of web-based and distance learning courses.

\section{CONCLUSIONS}

According to Reigeluth (2000), in the new concept of instructional design-oriented knowledge, construction should be given an important role to players in the educational activity about decision making and management of their own learning and teaching process. Risk assessment by students who develop their learning in the LMS is an important knowledge that determines the design of the activities and internal organization of available virtual tools.

Thus, the users should assess the type of tools available to students for the development of university distance studies on LMS. Students can contribute to take decisions about the best choices of methods, materials, teaching sequences, and so on. Understanding the users' risks involved in virtual environments is crucial, and in this sense, students could identify areas of interest, necessity, and the main incidents of the scenarios in which they study. People may feel frustrated when they are deprived of their expectations or are not able to complete their plans (Mandler, 1975; Handa, 2003).

This study focus on the main risks when using the LMS-aLF to develop distance virtual studies on the Spanish National University of Distance Education. The emphasis is concentrated in those ones related to "own and beyond students' circumstances” perceived as risks that could be controlled by the students and/or Higher Education institutions. These beyond main factors are: 4. "criticism of the educational community", "isolation from teachers", "warning from the authorities for not developing the program", "delegation of control” and "difficulty for students". 
The LMS success and efficiency through collaboration cannot be taken for granted (Dirkx \& Smith, 2004; Järvenoja \& Järvelä, 2009; Kreijns, Kirschner \& Jochems, 2002). In some cases, some LMS experiences may also evoke negative emotions and create new challenges for motivation when people experience conflict with their own characteristics, objectives, and requirements.

Findings from this study provide more understanding of the phenomenon of students' perception of risks in LMS. Based on these findings, we should provide recommendations to design the virtual environment that minimizes the risks, taking into consideration the design of learning experiences related to cultural and social contexts of the students population. This activity can be fostered by contextualized activities such as tasks, projects, and authentic cases based on real needs and demands, taking into account the explicit and implicit knowledge about the subject matter (beliefs, group norms). It is also important to generate rules that promote motivation and participation, a number of mechanisms of participants' accountability and the provision of structures to facilitate communication and interdependence.

On the other hand, in the context of adaptation to the European Higher Education Area, the teaching and learning process must be associated with competencies, and one of the biggest risks is associated with the assessment, which must be based on assessment progress, identify difficulties, and redirect the students' progress; in order that assessment should be primarily intended to provide feedback to students as part of their learning process to enable further progress.

A competent student should learn to manage in a proper way these changes, minimizing the risks and identifying what aspects can affect their own learning process, and take advantage of the elements that can positively influence this process and minimize those issues, which can hinder their learning. Professors and tutors should be aware of these risks from a double perspective: primarily, to guide teaching in the virtual context and select the type of activities and tools that minimize risks to students, and second, guide the design of the platform institutionally to provide feedback to teacher evaluation and minimize risks.

In this line, the integration of social networking, a better management of forums and chats, friendly apps and software that can be used ubiquitously could minimize the students' risks perception when using LMS in Distance Education.

\section{REFERENCES}

Álvarez, M. C. (Ed.). (2001). Developing critical and imaginative thinking within electronic literacy. Newark, DE: International Reading Association.

Ananiadou, K., \& Claro, M. (2009, September). 21st century skills and competencies for new millennium learners in OECD countries. NML country survey. In The New Millennium Learners International Conference, Brussels.

Artino, A. R. (2008). Understanding satisfaction and continuing motivation in an online course: An extension of social cognitive, control-value theory. In Annual meeting of the American Educational Research Association, New York, NY. Retrieved from

http://www.sp.uconn.edu/ aja05001/comps/documents/AERA_2008_SEM_Ar tino_FINAL.pdf

Artino, A. R., \& Stephens, J. M. (2007). Bored and frustrated with online learning? Understanding achievement emotions from a social cognitive, control-value perspective. Paper presented at the Annual meeting of the Northeastern Educational Research Association, Rocky Hill, CT. Retrieved from http://www.sp.uconn.edu/ aja05001/comps/documents/NERA07_AchEmotions_Artino\%2BStephens.pdf

Baker, E. (2003). Reflections on technology-enhanced assessment. Assessment in Education, 10(3), 421-425. doi: 10.1080/0969594032000148226
Brindley, J. E., Walti, C., \& Blaschke, L. M. (2009). Creating effective collaborative learning groups in an online environment. International Review of Research in Open and Distance Learning, 10(3), 1-18.

Curtis, D. D., \& Lawson, M. J. (2001). Exploring collaborative online learning. Journal of Asynchronous Learning Networks, 5(1), 21-34.

Daniels, P. (2009). Course Management Systems and Implications for Practice. International Journal of Emerging Technologies \& Society, 7(2), 97-108.

Dirkx, J. M., \& Smith, R. O. (2004). Thinking out of a bowl of spaghetti: Learning to learn in online collaborative groups. In T. S. Roberts (Ed.), Online collaborative learning: Theory and practice (pp. 132-159). Hershey, PA: Information Science Publishing. doi: 10.4018/978-1-59140-174-2.ch006

Do, S., \& Schallert, D. (2004). Emotions and classroom talk: Toward a model of the role of affect in students' experiences of classroom discussions. Journal of Educational Psychology, 96(4), 619-634. doi: 10.1037/0022-0663.96.4.619

Dodda, B. J., \& Antonenkob, P. D (2012). Use of signaling to integrate desktop virtual reality and online learning management systems. Computers \& Education, 59(4), 1099-1108. doi: 10.1016/j.compedu.2012.05.016

Ellis, R. (2009). A field guide to learning management systems. USA. American Society of Training and Development (ASTD).

Fletcher, G. H. (2007). Bloggers welcome here: Social networking tools appear poised to enter the school system. It's a breakthrough long overdue. TH E Journal (Technological Horizons in Education), 34(11), 8.

Garrison, D., \& Vaughan, N. (2008). Blended learning in higher education: Framework, principles, and guidelines. San Francisco, CA: John Wiley \& Sons.

Georgina, D., \& Olson, M. (2008). Integration of technology in higher education: A review of faculty self-perception. The Internet and Higher Education, 11, 18. doi: 10.1016/j.iheduc.2007.11.002

Glover, I., \& Oliver, A. (2008). Hybridisation of Social Networking and Learning Environments. In J. Luca \& E. Weippl (Eds.), Proceedings of the World Conference on Educational Multimedia, Hypermedia and Telecommunications 2008 (pp. 4951-8). Chesapeake, VA: AACE.

Gómez, E., \& Rodríguez-Marciel, C. (2012). PGDnet: a new problem-solving virtual learning environment. British Journal of Educational Technology, 43, 576-591. doi: 10.1111/j.1467-8535.2011.01224.x

Hahn, J. (2008). Born digital: Understanding the first generation of digital natives. Library Journal, 133(13), 105.

Handa, Y. (2003). A phenomenological exploration of mathematical engagement: Approaching an old metaphor anew. For the Learning of Mathematics, 23(1), 22-29.

Hickey, D. T., Moore, A. L., \& Pellegrino, J. W. (2001). The motivational and academic consequences of elementary mathematics environments: Do constructivist innovations and reforms make a difference? American Educational Research Journal, 38, 611-652. doi: 10.3102/00028312038003611

Hrastinski, S. (2006). Introducing an informal synchronous medium in a distance learning course: How is participation affected? The Internet and Higher Education, 9, 117-131. doi: 10.1016/j.iheduc.2006.03.006

Jackson, L. A., Von Eye, A., Biocca, F. A., Barbatsis, G., Zhao, Y., \& Fitzgerald, H. E. (2006). Does home Internet use Influence the academic performance of low income children? Developmental Psychology, 42, 429-435. doi: 10.1037/0012-1649.42.3.429

Järvenoja, H., \& Järvelä, S. (2005). How students describe the sources of their emotional and motivational experiences during the learning process: A qualitative approach. Learning, 15, 465-480.

Kopcha, T. J. (2012). Teachers' perceptions of the barriers to technology integration and practices with technology under situated professional development. Computers \& Education, 59(4), 1109-1121. doi: 10.1016/j.compedu.2012.05.014

Kreijns, K., Kirschner, P. A., \& Jochems, W. (2002).The sociability of computersupported collaborative learning environments. Journal of Education Technology \& Society, 5(1), 822.

Macdonald, J., \& Poniatowska, B. (2011). Designing the professional development of staff for teaching online: an OU (UK) case study. Distance Education, 32(1), 119-134. doi: 10.1080/01587919.2011.565481

Mandler, G. (1975). Mind and emotion. New York: Wiley.

Moyle, K. (2010). Building innovation: Learning with technologies. Australian Education Review, 56.

Park, S. Y., Nam, M.-W., \& Cha, S. B. (2012). University students' behavioral intention to use mobile learning: Evaluating the technology acceptance model. British Journal of Educational Technology, 43, 592-605. doi: 10.1111/j.14678535.2011.01229.x

Pekrun, R., Goetz, T., Titz, W., \& Perry, R. P. (2002). Academic emotions in students' self-regulated learning and achievement: A program of qualitative and quantitative research. Educational Psychologist, 37(2), 91-105. doi 10.1207/S15326985EP3702_4 
Reigeluth, Ch. (2000). La teoría elaborativa: orientación para la toma de decisiones sobre el alcance y la secuenciación. In Ch. Reigeluth (Ed): Diseño de la instrucción. Teoría y modelos (pp. 449-480). Madrid: Aula XXI Santillana.

Roberts, T. S. (2005). Computer-supported collaborative learning in higher education: An introduction. In T. S. Roberts (Ed.), Computer-supported collaborative learning in higher education (pp. 2-3). Hershey, PA: Information Science Publishing. doi: 10.4018/978-1-59140-408-8

Rosen, A. (2009). E-Learning 2.0: Proven practices and emerging technologies to achieve results. New York, NY: American Management Association.

Rosen, Y, \& Rimor, R. (2009). Using collaborative database to enhance students' knowledge construction. Interdisciplinary Journal of E-Learning and Learning Objects, 5, 187-195.

Rosen, Y., \& Salomon, G. (2007). The differential learning achievements of constructivist technology-intensive learning environments as compared with traditional ones: A meta-analysis. Journal of Educational Computing Research, 36(1), 1-14. doi: 10.2190/R8M4-7762-282U-554J

Rourke, L., Anderson, T., Garrison, D. R., \& Archer, W. (2001). Assessing social presence in screen text-based computer conferencing. Journal of Distance Education, 14, 51-70.

Rovai, A. P., \& James D. (2010). Why some distance education programs fail while others succeed in a global environment. Internet and Higher Education, 13, 141-147. doi: 10.1016/j.iheduc.2009.07.001

Rushkoff, D. (2010). Program or be Programmed. Ten Commands for a Digital Age. Or Books.

Sabry, K., \& Baldwin, L. (2003). Web-based learning interaction and learning styles. British Journal of Educational Technology, 34, 443-454. doi: 10.1111/1467-8535.00341

Shih, M., Feng, J., \& Tsai, C. C. (2008). Research and trends in the field of elearning from 2001 to 2005: A content analysis of cognitive studies in selected journals. Computers \& Education, 51(2), 955-967. doi: 10.1016/j.compedu.2007.10.004

Sierpinska, A., Bobos, G., \& Knipping, Ch. (2008). Sources of students' frustration in preuniversity level, prerequisite mathematics courses. Instructional Science, 36, 289-320. doi: 10.1007/s11251-007-9033-6

Stahl, G., Koschmann, T., \& Suthers, D. (2006). Computer-supported collaborative learning: An historical perspective. In R. K. Sawyer (Ed.), Cambridge handbook of the learning sciences (pp. 409-426). Cambridge, UK: Cambridge University Press. Retrieved from http://GerryStahl.net/cscl/CSCL_English.pdf

Traphagan, T. W., Chiang, Y. H. V., Chang, H. M., Wattanawaha, B., Lee, H., Mayrath, M. C., Woo, J., Yoon, H. J., Jee, M. J., \& Resta, P. E. (2010). Cognitive, Social and Teaching Presence in a Virtual World and a Text Chat. Computers \& Education, 55(3), 923-936. doi: 10.1016/j.compedu.2010.04.003

Warschauer, M. (2003). Technology and social inclusion: Rethinking the digital divide. Cambridge, MA: MIT Press.

Warschauer, M., \& Matuchniak, T. (2010). New technology and digital worlds: Analyzing evidence of equity in access, use, and outcomes. Review of Research in Education, 34(1), 179-225. doi: 10.3102/0091732X09349791

Weller, M. (2007). The distance from isolation: Why communities are the logical conclusion in e-learning. Computers and Education, 40, 148-159. doi: 10.1016/j.compedu.2005.04.015

Wu, B., \& Teoh, A. P. (2008). A Comparative Analysis of Learners Interaction in the Learning Management Systems: Does National Culture Matter? AAOU Journal, 3(1), 1-16.

\section{ACKNOWLEDGMENT}

Funded by: Ministry of Science and Innovation, Spain. Funder Identifier: http://dx.doi.org/10.13039/501100004837 Award: EDU2010-17420 